\title{
(息)
}

Citation:

Serra, P and Soler, S and Prat, M and Vizcarrac, M and Garayd, B and Flintoff, A (2016) The (in)visibility of gender knowledge in the Physical Activity and Sport Science Degree in Spain. Sport, Education and Society. ISSN 1470-1243 DOI: https://doi.org/10.1080/13573322.2016.1199016

Link to Leeds Beckett Repository record:

https://eprints.leedsbeckett.ac.uk/id/eprint/2722/

Document Version:

Article (Accepted Version)

The aim of the Leeds Beckett Repository is to provide open access to our research, as required by funder policies and permitted by publishers and copyright law.

The Leeds Beckett repository holds a wide range of publications, each of which has been checked for copyright and the relevant embargo period has been applied by the Research Services team.

We operate on a standard take-down policy. If you are the author or publisher of an output and you would like it removed from the repository, please contact us and we will investigate on a case-by-case basis.

Each thesis in the repository has been cleared where necessary by the author for third party copyright. If you would like a thesis to be removed from the repository or believe there is an issue with copyright, please contact us on openaccess@leedsbeckett.ac.uk and we will investigate on a case-by-case basis. 


\section{The (in)visibility of gender knowledge in the Physical Activity and Sport Science Degree in Spain}

Pedrona Serra ${ }^{\mathrm{a}}$, Susanna Soler ${ }^{\mathrm{a} *}$, Maria Prat $^{\mathrm{b}}$, María Teresa Vizcarra ${ }^{\mathrm{c}}$, Beatriz Garay $^{\mathrm{d}}$ and Anne Flintoff ${ }^{\mathrm{e}}$

${ }^{a}$ National Institute of Physical Education (INEFC), University of Barcelona,.

Barcelona, Spain; ${ }^{b}$ Department of Didactics and Corporal Expresion. Univesitat Autònoma de Barcelona. Cerdanyola, Spain; ${ }^{c}$ Didactics and Musical, Plastic and Physical Expression Department. Universidad del País Vasco (UPV/EHU). Vitoria, Spain; ${ }^{d}$ Department of Education and Sport. Universidad del País Vasco (UPV/EHU). Vitoria, Spain; ${ }^{e}$ Diversity, Equity and Inclusion Research Centre, Leeds Beckett University, Leeds, England

\section{Pedrona Serra}

Postal address: Avda de l'Estadi, 12-22, 08038 Barcelona. Phone: (0034) 934255445

Email: pedronaserra@gencat.cat

\section{*Susanna Soler (Corresponding author)}

Postal address: Avda de l'Estadi, 12-22, 08038 Barcelona. Phone: (0034) 934255445

Email: ssoler@gencat.cat

\section{Maria Prat}

Postal address: Plaça Cívica, Campus de la UAB, 08193 Cerdanyola.

Phone: (0034) 935813193. Email: maria.prat@uab.cat

\section{María Teresa Vizcarra}

Postal address: Calle Juan Ibáñez de Santo Domingo, 1, 101006 Vitoria.

Phone: (0034) 945014182. Email: mariate.bizkarra@ehu.es

\section{Beatriz Garay}

Postal address: Lasarte Ataria, 71 / 01007 Vitoria. Phone (0034) 945013513

Email: beatriz.garai@ehu.eus

\section{Anne Flintoff}

Postal address: Headingley Campus, Leeds LS6 3QS. Phone: (0113) 8126148

Email: a.flintoff@leedsbeckett.ac.uk 


\section{Acknowledgements}

This work was supported by the "Ministerio de Economía y Competitividad, convocatoria de ayudas de Proyectos de Investigación Fundamental no orientada" under Grant [DEP201231275] and National Institute of Physical Education of Catalonia (INEFC) under Grant [PINEFC-2012]. 


\begin{abstract}
This paper draws on research that aimed to explore the construction of gender relations in sport and physical education (PE) through a national study of Spanish university degree curricula. Spain is a useful case study through which to explore gender knowledge within sport and PE degrees, because, unlike many other countries, it has a common, national curriculum framework for its Physical Activity and Sport Science (PASS) degrees. In addition, it has recently passed a new law concerning the introduction of gender knowledge in higher education. Drawing on Bernstein's (1990) framework of the pedagogic device, this paper examines how this higher education gender policy becomes recontextualised as universities and lecturers interpret and translate this into the pedagogical texts that make up the PASS curricula. Purposive sampling was used to select 16 of the 37 universities offering PASS degrees in 2012/2013. The research analysed 16 PASS documents at the degree level, and 763 individual subject handbooks. Using discourse analysis, the results showed where and how gender knowledge was incorporated and the extent to which the topic was presented coherently throughout the documents. The analysis revealed five categories of the (in)visibility of gender knowledge within the universities' instructional discourse. Gender knowledge is largely ignored in PASS curricular documentation, appearing, at best, in highly superficial ways. Despite a national policy requirement on universities to incorporate gender knowledge, this study shows how recontextualisation processes within specific universities' pedagogic devices operate to marginalise such perspectives within PASS curricula. The research also revealed the significance of individual agents committed to gender equity being situated, and having influence, throughout the pedagogic device. The paper concludes that without a much wider, critical engagement in knowledge about gender equity, PASS degrees will continue to reproduce rather than disrupt the gender relations that have traditionally characterised the field.
\end{abstract}

Keywords: Gender Knowledge, Higher Education Curriculum, Physical Education, Sport Science, Pedagogic Discourse 


\section{Introduction and background}

This paper draws on research that aimed to explore the construction of gender relations in sport and physical education (PE) through a national study of Spanish university degree curricula. Spain is a useful case study through which to explore the changing nature of gender relations within sport and PE degrees, because, unlike other European countries, it has one common, generic four-year undergraduate curriculum related to physical activity, physical education and sport (albeit with some optional subjects), called the Physical Activity and Sport Science (PASS) degree. All students study the PASS degree, regardless of whether they wish to specialize in teaching, coaching, managing or health, or where in the country they study ${ }^{1}$. An examination of the Spanish PASS curriculum offers an opportunity to examine the changing nature of gender relations and the position of gender knowledge within the broader field.

In its analysis of PASS curricula across all regions of Spain, the study extends existing research, which has tended to focus either on the curricula of a single, or small numbers of institutions (Dewar, 1990; Flintoff, 1993), or on university teachers' or students' attitudes towards gender equity (Amsterdam, Knoppers, Claringbould, \& Jongmans, 2012; Dowling 2008; 2011). In addition, Spain, like many other European countries, has recently introduced new equality laws. One outcome of the introduction of the 2007 Equality Act (Organic Law 3/2007) was the requirement for all universities to redevelop new degree programmes to overtake their statutory duties. The Act enshrined equality of outcomes between the sexes. Article 25 of the Act specifically states that higher education (HE) should promote gender knowledge through its inclusion into appropriate study programmes, the development of specific postgraduate courses and research projects in gender-related topics. Specifically pertinent to this research, the university Organic Law 4/2007, which required a new programme for all university degree courses, makes special mention of equality between men and women. Thus, the Spanish context offers the opportunity to assess whether, and how, commitments to gender equality at state level, get translated into university curricula. However, even within similar supportive legislative and policy contexts, research elsewhere has shown the struggles to embed gender knowledge within the higher education curriculum (Arreman \& Weiner, 2007), and this seems to be particularly the case with the field of PE and sport studies (Wright, 2002). This study therefore provides a timely analysis of the nature of PASS knowledge in contemporary times in Spain, and adds to work documenting the struggle for critical knowledge in universities in contemporary, neoliberal times (Dowling, 2011; Evans \& Davies, 2014; Kårhus, 2010, 2012). Given the important relationship between the construction of school PE and university curricula (Macdonald, Kirk, \& Braiuka, 1999) the case for gender knowledge in the university education of those destined to be the next generation of PE teachers, sports coaches or managers, seems uncontentious.

Drawing on Bernstein's (1990) theoretical framework, this study had the following research questions. How is the mandatory Spanish policy on gender equity in higher education applied withinPASS? How has HE gender policy been drafted, reproduced and relocated by universities and lecturers through the pedagogic device? To what extent is gender knowledge (in)visible within PASS curricula? How are gender relations reproduced or challenged through PASS?

\footnotetext{
${ }^{1}$ Those wishing to become a PE teacher in secondary school are required to undertake a further one year, masters course.
} 


\section{Gender knowledge in higher education and within PASS}

Whilst a detailed analysis of the shifting positioning of gender knowledge within universities and PASS is outside the scope of this paper, it is worth highlighting a number of salient points ${ }^{2}$.

Firstly, the way in which 'gender' and 'gender knowledge' is articulated and understood is highly contested and has changed over time, influenced by social, political and economic changes and by developments both within and outside education (Francis, 2006). Francis (2006), for example, trace the changing trajectory of feminist theories about gender, highlighting their diversity, but also some of the struggles and impasses that characterise the field. Central to these has been how best to theorise and account for difference and experience, including biological difference, but also more recently those on the basis of race, class, sexuality and disability and their intersection with gender (Davies, 2008).

In relation to knowledge, authors have variously drawn upon cultural reproduction/resistance, critical pedagogy and post-structural theories to explain the privileging of patriarchal over other forms of knowledge (e.g. Arnot 2002; Gore, 1993; Paechter, 2000). Whilst useful, as Singh (2002) points out, these fail to illuminate the processes by which some forms become privileged over others. Although Bernstein developed his concept of the pedagogic device to explain the reproduction of class relations, Arnot (2002) and Delamont (2014) have argued persuasively that it can be applied equally well to gender. For Arnot (1982), male hegemony operates through the ways in which schools (and universities) transmit a dominant 'gender code' - different definitions of masculinity and femininity, that although open to resistance, nevertheless 'frame' the type and possible responses that can be made to it. Bernstein's concept of pedagogic device, explored further below, explains how particular gender codes are constructed and reproduced.

Secondly, there is no necessary correspondence between the development of feminist knowledge and improved educational practice. Although welcome, the increasing sophistication in feminist theories raises challenges for policy and practice, which often lags well behind theoretical advances (Maguire, 2006). Different feminist theories exist precisely because there are different views of what is at issue, and therefore what needs to be changed. In addition, state policies will be 'differently constructed and enacted because of different histories, cultures and systems of power' (Maguire, 2006, p. 121). For example, whilst contemporary feminist theory might contest binary conceptions (e.g. man/woman), Maguire (2006) argues the 'seduction of binaries' seem to have been part of gender policy work, at least in the UK, for some time, with its focus on whether girls (or boys), as a group, are performing at the same level. Mirroring wider global educational policy, the focus has been largely on outcomes (pupil achievements) rather than processes (teachers' pedagogies, pupils' learning experiences). Despite this shift in focus, theoretically, there is continued empirical data to suggest that gendered patterns of subject choice and achievement remain (Pfister, 2010). In Arnot's (2002) terms, the increased new political concerns around gender have led to a recontexualisation of gender codes; 'the conditions for sustaining male power may have shifted, but are still in place' (Arnot, 2002, p. 195).

\footnotetext{
${ }^{2}$ See David (2014) and Skelton, Francis, \& Smulyan (2006) for good overviews of key debates and developments in gender and education; see Scraton (2013); Scraton \& Flintoff (2013) for similar overviews in gender, $\mathrm{PE}$ and sport.
} 
Given the points above, it should not be surprising to learn that the introduction of legislation and/or gender policy does not necessarily bring about the change intended. Policies are always open to interpretation and whether (or how) they are enacted within local contexts. For example, like a number of other countries around the same time, England developed a set of national criteria for teacher education in 1984 which established gender equality (as well as race) as a compulsory professional issue for all courses to address (Equal Opportunities Commission, 1989). A survey of practice five years later, showed the national picture to be one of 'benign apathy' — with pockets of good practice linked directly to the work of committed individuals. Worryingly, almost twenty years on, the Carter Review of Initial Teacher Training (Department for Education, 2015) set up to 'identify core elements of high quality' (p.4) training makes no mention of the need for future teachers to engage in issues of equity, apart from special educational needs and disability. With or without specific legislation to introduce gender knowledge into teacher education in England, it seems that the outcomes are the same: any positive practice in relation to teaching for or about gender equality relies on the commitment of specific individuals.

These findings are mirrored in Spain where universities need to meet the Spanish National Agency for Quality Assessment and Accreditation's (ANECA) verification and accreditation protocols in order to have their programmes approved. One requirement is to ensure that programme competences '... should be defined taking into account fundamental rights and the equality of opportunities between men and women' (ANECA, 2012, p. 21). Despite these guidelines, and the existing legal framework in which universities are situated, research reveals little evidence of even this liberal version of gender knowledge in Spanish university programmes, particularly those within teacher education (Anguita, 2011; Aristizabal \& Vizcarra, 2012; Donoso \& Velasco, 2013; Pezzi et al., 2011). Different justifications for this 'invisibility' of gender knowledge within Spanish university curricula are rehearsed: on the one hand, the vagueness of the new policy, on the other hand, the failure of the 'mainstreaming approach' to gender because of lecturers' 'gender blindness' or the 'fear of feminism' (Weiner, 2000).

Similar issues arise in the specific field of PE and sport where several studies have demonstrated lecturers' lack of commitment to equity and social justice issues generally; lecturers either view teaching about gender equality as unnecessary or irrelevant to their particular subject teaching (Dowling, 2008; Flintoff, 1993; Prat \& Flintoff, 2012). Knowledge about gender relations or inequalities in PE becomes a secondary or peripheral topic (Flintoff \& Fitzgerald, 2012). It may, for example, become diluted as part of a more generic consideration of equality issues that also includes special educational needs or race equality (Prat \& Flintoff, 2012), or positioned as an optional subject, so having to compete with others that the students may consider 'more attractive' or 'relevant' (Dowling, 2013). As a consequence, the incorporation of gender knowledge often depends exclusively on the goodwill of individual lecturers who are aware of and committed to the issues.

It appears that the centrality of the body in sport and PE, coupled with the dominance of a performative discourse where male-defined standards of power and strength predominate, legitimate a sex-difference approach to gender knowledge. These discourses and practices reproduce the dominant gender code within PE and sport- one that views women as different or weaker to men, or as not interested (Vertinsky, 1992; With-Nielsen \& Pfister, 2011), thus constituting its hegemonic knowledge (Dowling, 2013; Flintoff, 1993; Wright, 2002). 


\section{Theoretical framework}

Bernstein's (1990) conceptual framework provides a useful lens to analyse how knowledge about gender is included in PASS curricula. His approach to educational policy sociology is particularly helpful in policy analysis in terms of investigating the relations between categories of knowledge produced by agents and agencies at different levels, and in different sites (Penney \& Evans, 1999; Svendsen \& Svendsen, 2014). As Kirk and Macdonald (2001) and Kårhus (2010) argue, Bernstein's theory of the social construction of pedagogic discourse can help understand curriculum change, and how knowledge gets recontextualised between and across different fields. Although Bernstein's theories appear to be regaining prominence in educational research more widely, they have yet to be applied, in any sustained way, to an analysis of gendered knowledge within PASS (Whatman \& Singh, 2013).

Bernstein (1990) argues that pedagogic discourse is produced, recontextualised, and reproduced across three fields: primary, secondary and recontextualising fields. In each field, agents are at work. The primary field includes state and HE policy makers, members of the scientific community, and people from the worlds of sport, leisure and health. According to Kirk and Macdonald (2001) these agents produce discourse through their practices which generate meanings, values, and knowledge, and these are the raw materials from which educational programmes are created. Bernstein (1990) refers to the raw materials as regulative discourse when they are used to construct educational programmes.

Regulative discourse is 'the moral discourse which creates order, relations and identity' (Bernstein, 2000, p. 32). In relation to gender knowledge, this raw material or moral discourse is diverse, and often contradictory. For example, one key contradiction relevant to this study is the gap between an increasing recognition of the importance of gender equality in political discourse and national policy, and the patriarchal discourses and practices evident within PASS and PE professional culture (Dowling, 2008; Hay \& Macdonald, 2010; Webb \& Macdonald, 2007). In addition, the strong neoliberal discourse, evident across educational institutions globally, challenges and contests the need for feminism and gender knowledge (Donoso \& Velasco, 2013; Scraton, 2013).

The secondary field is the field of reproduction, where the main goal is knowledge transmission. Agents acting in this field include lecturers, students and administrators. In the secondary field, instructional discourse is expressed through educational programmes and official curricula. This research is interested in the extent to which gender knowledge is evident in specific degree programme curricula (programme specifications) and subject handbooks ${ }^{3}$. Between these two fields exists the recontextualising field, where regulative discourse is reconfigured into instructional discourse. Kårhus (2010) argues that 'when universities and university colleges develop programs of study and construct curricula, they can be located in the recontextualising field' (p. 232).

\footnotetext{
${ }^{3}$ In Spain, the degree course document, or programme specification is called the 'Memoria Oficial del Título'. By subject handbook, we are referring to the written document for particular modules, or courses within an overall degree programme e.g. physiology, or sociology. All Spanish universities are required to publish their programme specification and individual subject handbooks on the internet. They also publish the names of the Commission, the group of staff responsible for drafting the programme specification.
} 
Every time that a discourse 'moves from one position to another, there is a space in which ideology can play' (Bernstein, 2000, p. 32). The recontextualising principle selectively appropriates, relocates, refocuses and relates to other discourses to constitute its pedagogic discourse order. The pedagogic recontextualising field is composed of positions (oppositional and complementary) constructing an arena of conflict and struggle for dominance. In this recontextualising field, the drafting of a new study programme, as in the case of a PASS degree, brings to the fore different conflicts and resistance to innovative practice (Tomás, 2012). The process of transforming regulative discourse into instructional discourse allows for challenge and opposition by different agents positioned within individual institutional contexts. For this reason, in order to understand the extent to which gender knowledge is incorporated into the new programmes and subject handbooks as instructional discourse, the existence of these conflicts and power struggles in the pedagogic recontextualising field needs to be acknowledged. Importantly, Bernstein (2000) points to the significance of those who control the pedagogic device 'because whoever appropriates the device has the power to regulate consciousness. Whoever appropriates the device appropriates a crucial site for symbolic control' (p.38).

\section{Methodology}

In this research we analysed the 16 universities' PASS curricula materials that were publicly available, by law, on their web pages. These included the programme specifications and associated subject handbooks, together with the so-called 'White Book' for PASS degrees in Spain (ANECA, 2005). The White Book is a PASS-specific guidance document developed by a national group of PASS academics ${ }^{4}$. These documents constitute the official documents of each faculty and each subject, and they are the official consultative documents for current and future students. Our sample comprised 16 of the total 37 universities offering the PASS degree in 2012/2013. Using purposeful sampling (Patton, 1990), we selected the universities from each autonomous community (region) that had the longest history of offering PASS degrees in their region. In doing so, we recognise that some of the long-standing programmes might also have been those with deeply embedded, traditional gendered practices, and it might have been useful to include some newer programmes. However, in making our selection in this way, our sample did include a few universities that had a tradition of gender research. Altogether, we analysed 16 PASS programme specifications and the 763 associated subject handbooks.

ANECA (2012) states that each subject handbook must have a common structure which includes, among other aspects, the name of the subject, whether it is compulsory or optional, the competences and objectives, the content, the teaching activities, the system of assessment, and the bibliography. Despite these guidelines for handbook structures, there was significant variation in those analysed for this research. Each university had its own specific template for handbooks - some were very slim allowing for significant interpretation and contribution by lecturers in their development of the day-to-day teaching and learning activities, while others provided much more detailed information.

The research used discourse analysis to explore where gender issues appear, and the extent to which there was coherence to their inclusion within handbooks. Since

\footnotetext{
${ }^{4}$ Other subject fields have similar 'White Books' to describe the broad characteristics of their curricular content.
} 
language is a social action that constitutes reality, discourse analysis explores how language contributes to reproduce power relations (Van Dijk, 2009), and involves subjecting the texts to several levels of analytical reading. The first step consisted of encoding of the material and processing the text by reading them on their own terms. Acknowledging the contested and changing articulation of gender noted above, the following search terms were used: coeducation; mixed; discrimination; equality; equity; feminism; sex; gender; men or man; and women or woman. We remained open to adding to this list if different terms emerged from our readings, and we also noted the context in which they were used. How, or whether gender is referred to, contributes to its (in)visibility in formal content knowledge - important because of how language contributes to reproducing power relations (Bernstein, 2000). The second step was to code each handbook according to how gender knowledge appeared. Did it, for example, appear in the subject handbook competences and objectives, and then track through into the content and model of assessment, supported by appropriate literature - or was it merely tagged on, appearing only in one aspect of a subject handbook? To ensure consistency in the use of the typology, members of the research team classified each document individually, and re-analysed any handbook where differences between the team were evident. Our analysis resulted in a typology, described further below, that describe five levels of gender visibility and coherence in relation to the subject handbooks. The typology allows for a description of where and how (and to what extent) gender knowledge appears within the PASS instructional discourse, both across different universities, but also within the subject areas within particular programmes. We used this level of analysis in creating Graph 1 and 2. In addition, we analyses how gender knowledge and inequalities were described within the handbooks, using qualitative thematic analysis. We describe below, how this analysis identified the dominant gender code (Arnot, 2002) as one of sex difference rather than one based on power relations.

\section{Results}

In this section, we draw on Bernstein's concept of the pedagogical device to analyse how gender knowledge has been recontextualised and is reflected in the construction of PASS knowledge. The first part maps where and how gender knowledge is evident within official PASS documentation. The second part focuses on how this official discourse on gender is recontextualised by lecturers and appears within specific subject handbooks at each university. The final part considers some of the few specific cases where gender knowledge is either an explicit focus of a subject or evident within the competences of a programme specification as a result of the struggles of individuals.

In Figure 1, we illustrate the documents included in our research in relation to Bernstein's theoretical framework.

Figure 1. Bernstein's theoretical framework applied to the policy and curriculum documents of the Spanish PASS Degree

\section{i) The recontextualisation of gender knowledge in the White Book and Programme Specifications}

The PASS White Book exerts a major influence on the development and characteristics of the curriculum content at each university (Márcia, Soler, Costes, \& Lavega, 2013). Our analysis of its content reveals that gender is only included in the first section which considers the characteristics of the labour market for which PASS graduates are being prepared. Beyond this brief mention, there is no further reference to 
gender in the following chapters, despite, as highlighted earlier, the different laws to promote gender knowledge inclusion in the primary field. In addition, this acknowledgment of gender in relation to labour market is not translated into pedagogic discourse within the curricula, and gender is absent in the sections that lay out the knowledge, competences and professional profiles, and in the design of the educational programme. In this way, the PASS professionals that developed the White Book acting as key agents in the recontextualising field - have been instrumental in gender knowledge being omitted from this level of instructional discourse.

However, beyond what is established in the White Book, each PASS faculty, in accordance with its university guidelines, designs their own study programme, coordinated by a Commission (i.e. the course development team). At this stage, there is an opportunity to rectify the gender-blindness evident in the White Book.

In 11 out of 16 programme specifications, gender appeared in at least one competence. However, further analysis shows that in eight of these 11 cases, sex or gender appears in relation to a more generic consideration of 'equality', alongside age, disability, cultural diversity or religion for example. In only two universities does gender appears as a single competence. It is also evident in some cases that the competence appears to have simply been transposed from the broader university guidelines, rather than written specifically and appropriately contextualised by the PASS academics. For example, a generic equity competence from University $\mathrm{F}^{5}$ reads:

\footnotetext{
To be able to share the knowledge, abilities and skills acquired to promote a society based on the values of freedom, justice, equality and pluralism. The University F aims to guarantee that its graduates contribute to achieving a society based on equality, a concept which includes not only respect for cultural diversity but also situations related to gender, disability and the fight against all types of discrimination on the grounds of religion, culture, politics or any others, particularly important in the field of professional development associated with the degree.
}

In the remaining five programme specifications gender disappears, replaced by terms such as 'human rights' or 'democratic values', or it is discarded in favour of other social groups that are explicitly mentioned such as those constructed on the basis of culture, disability, or age. These examples illustrate the prevalence of a liberal discourse, focused on equal access, rather than power relations and unequal outcomes. Our data reveal the inconsistent ways in which gender is evident within the pedagogic discourse at the significant level of the White Book, and the programme competences. The patriarchal traditions and neoliberal discourses within the professional culture act to reconfigure the legal requirements for gender knowledge within the field of PE and sport. At this first step, within the recontextualising field, national policies lose influence in the face of the hegemonic 'raw material', present within the professional culture (Kirk \& Macdonald, 2001).

\section{ii) Gender knowledge recontextualised within the subject handbooks}

Whether or not, and how, gender is explicitly named in a competence within a PASS programme specification is no guarantee of it being included in the actual individual subject areas of the degree. Similarly, the opposite is true: its absence in the programme specification does not prevent gender from having visibility in some specific subject areas. The pedagogic device continues to function as the instructional discourse is defined, as our data demonstrate.

\footnotetext{
${ }^{5}$ All universities are identified by a capital letter to remain anonymous.
} 
Once each faculty has written the programme specification, lecturers have to design the handbooks for each subject. At this new stage, still within the recontextualising field, lecturers draw from the competences established for the degree programme to develop the specific objectives, establish the content and the teaching activities, and construct the bibliography for their subject area. According to Bernstein's (2000) theory of the pedagogic device, lecturers can contribute to the recontextualising field by making their teaching guidelines more or less dependent on materials created by external agents, such as the White Book or programme specification. Depending upon the guidelines of each university, lecturers have more or less room for manoeuvre, and can add aspects not listed in the programme specification, or conversely, omit aspects.

Our analysis established a typology to describe five levels of gender visibility, including its coherence, in relation to the subject handbooks. Exclusive, when gender knowledge is the sole focus studied in the subject. Embedded, when gender knowledge is not the only topic covered in the subject but it is included in all the sections of the document (e.g. within the specific objectives, the content and the teaching activities, and the bibliography). Partial, when it is only introduced in maximum of two sections of the handbook. Superficial, when gender only appears in the 'competences' section. None, when there is no reference to gender at all throughout the handbook. We use the typology as a heuristic device, designed to show that instructional discourse is always the outcome of struggle and contestation, not just between the primary and secondary fields, but within the secondary fields themselves. These outcomes of such struggles are reflected in the five different levels of the typology.

Graph 1 illustrates that, at least in a superficial sense, some knowledge about gender appears within all the universities' PASS degrees. By looking closely, in seven universities, subjects where gender is appears in a superficial or partial way, represent $20 \%$ or more of their whole degree courses. We might argue, however, that these universities are paying political lip-service to the incorporation of a gendered perspective in their PASS courses - gender appears at the level of course or subject competences, but disappears at the level of specific subject curricula. Our typology illustrates how the recontextualising process is not uniform across different universities, and points to how some agents have more freedom to determine what to teach than others. As will be discussed further below, the influence of significant agents or individuals (with or without a commitment to gender knowledge) means that there are always struggles and contestation over the place and extent of gender within the instructional discourse.

\section{Graph 1. Percentage of subjects in each category, by university}

Graph 1 also shows whilst eight of the universities selected have at least one subject area classified as being embedded or exclusive, in a further eight universities there are none. It means that in 50\% of the sample, gender knowledge is not included in a comprehensive way in any subject. Whilst there are examples of subject areas where gender is integrated throughout all sections of the subject handbooks, their limited number - overall and at each university - means that it difficult to characterise the inclusion of gender knowledge as anything other than superficial in PASS programmes. Interestingly, in the four universities where there are exclusive or embedded subjects, gender is less evident elsewhere in the degree (i.e. C, D, G, and P). It appears that where specific lecturers address gender knowledge, others have an excuse to ignore it (Donoso \& Velasco, 2013; Prat \& Flintoff, 2012). As a whole, the embedded or exclusive development occurs in only 15 subjects out of the total of 673: 14 of the subject 
handbooks classified as embedded and one classified as exclusive. Table 1 details the characteristics of the 15 subjects where gender is embedded or is the exclusive focus.

Table 1. Subjects that address gender in an 'embedded' or 'exclusive' way

Our analysis highlights these are minimum tariff in relation to ECTS credits and that many of these subjects are optional (see Table 2). Gender knowledge is therefore either tightly framed as separate, or marginalised in relation to the dominant patriarchal knowledge base.

Table 2. Number of compulsory/optional subjects that deal with gender knowledge

Table 1 shows the minimum presence of gender knowledge across all 763 subjects. The 14 subjects where gender knowledge is embedded represents just $1.8 \%$ of the total, with 38 (5\% of the total) at a partial level. As well as where gender knowledge appeared, our analysis was also interested in how it was presented. In the majority of cases, the dominant gender code (Arnot, 2002) is one of sex difference, where women are constructed as different to men, and in need of 'special' treatment. For example, women were often identified as a specific 'population', alongside others such as immigrants or 'disabled people' (sic). The following is an example of this in curriculum knowledge relating to nutrition. The handbook describes the content as 'Special nutritional considerations in physical activity: child and teenage athlete, woman athletes, vegetarian athletes, etc.' (University D). With this discursive technique, knowledge about men and the male body gets constructed as universal and normative. The different nutritional demands of women athletes to men (due to menstruation, etc.) may well be valid knowledge for PASS students to learn, but the exclusion of other kinds of knowledge that might address gender relations and inequalities, works to reproduce a dominant gender code where male hegemony remains intact.

Graph 2 shows this gender code at work: $74.6 \%$ of handbooks exclude any knowledge of gender, with a further $18.5 \%$, like Pezzi et al. (2011) work has also revealed, addressing this only at the level of a programme competence, with no evidence of how this can be achieved via the associated objectives or subject knowledge content.

Graph 2. Percentages of subject handbooks incorporating gender knowledge

Our data and analysis outlined above shed light on how gender knowledge disappears as it moves through the recontextualising field into the instructional discourse within the Spanish PASS degree.

iii. Space for gender knowledge in instruccional discourse: the struggles and significance of individuals

It is interesting to analyse those few cases where there is an explicit presence of gender knowledge, whether that is due to the existence of a subject area where gender is the exclusive focus, i.e. University $\mathrm{C}$, or due to the incorporation of terms linked to gender in several competences and subjects, i.e. University A. In each of these cases, too, recontextualised gender knowledge also struggles to find a place.

Although we specifically included universities with a tradition in gender studies in our sample, we found only one, University $\mathrm{C}$, to have a specific subject solely focused on gender, 'Women and Sport'. Even with a strong history of gender research within the university, within PASS it appears only as an optional subject, and it is only worth 3 ECTS, just $1.25 \%$ of the overall degree programme. 
In addition, it is worth noting that before the reform of the PASS degree, we are aware that there were at least two other faculties that offered specific, gender-related subjects (albeit as optional elements of the programmes): University $\mathrm{G}$ had two subjects 'Women and sport' and 'Multiculturalism and gender in PE', and University B 'PE, gender and sport' (Alfaro \& Vázquez, 2007). One of the effects of the redrafting of the universities' PASS degrees in 2007 was a significant reduction in the amount of optional subjects. As a result, although there is some anecdotal evidence to suggest that these gender electives initially survived the redrafting process, they have since been dropped from the programme due to 'lack of demand'. At University G, gender issues are still visible, but are now included within a broader subject that also deals with questions of cultural diversity and 'values education'.

The analysis of the outcomes of the curriculum reform at these two faculties demonstrate issues highlighted earlier; firstly, that if gender is offered as an optional subject, it can soon disappear through 'lack of demand' if set against electives that are deemed more 'attractive' or 'relevant' to students (Anguita, 2011). Secondly, the reduction of choice as a consequence of the new curriculum development has resulted in power struggles whereby gender knowledge has lost out in the recontexualising process (Márcia et al., 2013; Tomás, 2012).

A final interesting case is University A. Here gender, as well as socio-cultural knowledge as a whole, is well represented within the design of the PASS program with $25 \%$ of the Program Specification competences including the term 'gender'. It is also the faculty that has the most subjects where gender is embedded, (where gender appears in all sections of the subject handbook, from objectives, content and through to the bibliography) - a total of four, all of which are compulsory; and six subjects where gender is partially visible (where gender appears in some sections of the handbook (four of these are compulsory). Even so, whilst $70 \%$ of the subject handbooks mention a competence linked to gender there is no corresponding content or objectives that develop this within the rest of the document. Our analysis of the members of the Drafting Commission for the Study Programme for this degree reveals that one of those involved is a specialist in gender studies - someone who had clearly influenced the drafting of the competences for the degree, but who has not been able to ensure that these were translated into actual subject curricula.

The presence of gender knowledge in the PASS programmes reflects then, the influence and commitment of those drafting the curriculum; where there is no commitment, and/or insufficient capacity to influence the process, gender knowledge fails to be introduced coherently throughout the study programme.

\section{Concluding comments}

Our research set out to map the extent of gender knowledge within the PASS degree across Spain at a time when the policy and legislative context in support of gender equality was (and arguably remains) strong. The picture revealed is of a significant gap between national and local contexts in terms of the visibility and legitimation of gender knowledge. Whilst gender equity is visible and strongly legitimated in the primary field, via the Equalities Law, and associated Universities' Organic Law, our research shows how it becomes repositioned and marginalised during the process of transforming regulative discourse into instructional discourse within the recontextualising and secondary fields of PASS. Gender equality discourse has been shown to be a marginal discourse within PASS. The dominant gender code within 
PASS continues to reproduce a sex difference discourse, which works to position women as inferior to men, and in need of 'special' treatment.

Whilst some may not be surprised by our data, it is nevertheless significant, not least because of its national scope, painting as it does a disturbing picture of the state of play of gender knowledge within Spanish PASS degrees. Our work coheres with Kårhus' (2012) recent call to examine the systemic changes taking place in the subject area. Our research reveals the significant national and institutional marginalisation of gender equality discourses within university PASS curricula, extending previous studies that have been limited by their focus on individual institutions or policies (Dowling, 2008, 2013; Flintoff, 1993; Prat \& Flintoff, 2012).We have found Bernstein's theory of the pedagogic device useful in showing how, despite the legal framework in favour of the incorporation of gender knowledge within higher education curricula, this does not happen automatically. Agents involved in the primary, recontextualising and secondary fields, who 'produce' and 'reproduce' the pedagogic discourse, influence whether or not gender is introduced into the degree. In this struggle for knowledge, our research has shown the significance of individual agents committed to gender equity being situated, and having influence, throughout the pedagogic device. The emancipatory potential promoted by the Spanish legal and policy frameworks disappears through the recontextualisation process, as male hegemony continues to control the pedagogical device.

It is important to note that whilst our analysis can highlight the (in)visibility of gender within the official PASS documentation, it can say little about how or whether this get enacted in everyday lecturers' pedagogical practice. In this sense, our research has not done full justice to Bernstein's theory of the pedagogic device in that it has presented only one view of the processes of recontextualisation - through textual analysis. Others have shown the disjuncture between policy texts and teachers' practice (Ball, Maguire, \& Braun, 2012; Hay \& Macdonald, 2010; Penney \& Evans, 1999; Soler, 2009).There is a need for future research that focuses on examples where there have been positive outcomes in relation to gender equality and PASS. For example, studies such as Oliver and Kirk (2014) or Enright and O'Sullivan (2010) show the significance of co-constructing a gender-relevant curriculum (Gorely, Holroyd, \& Kirk, 2003) with the learners, and, acknowledging the relational aspect of gender, the importance of examining the processes of teaching and learning, not just a 'finished' curriculum text.

A further area that might prove fruitful in supporting the inclusion of gender knowledge in PASS is the influence of other policy fields, such as those found within research and innovation. As our findings show, one of the reasons why gender knowledge in PASS is largely invisible is because it appears within the socio-cultural, rather that the bio-behavioural sciences, where the latter knowledge predominates. Our findings show both that socio-cultural knowledge is marginal within PASS, and gender knowledge struggles for space within socio-cultural subjects, as it is set against other equality issues, such as culture or disability. There is a need to widen our conception of gender knowledge to incorporate all aspects of knowledge, practice and research within our field and move beyond the cursory consideration of sex difference knowledge that currently predominates. The recent policy agendas of the European Union in relation to research and innovation through the Horizon 2020 programme are strongly in support of this. We would agree with Buitendijk and Maes' (2015) recent paper on gendered research and innovation, aimed at universities, which notes, that a systematic, due regard for gender related issues 'in all stages and all fields' (p.3) of research, is necessary if we are to conduct excellence research capable of meeting the global 
challenges that we face. To move beyond the current small and tenuous position of gender knowledge within PASS, such a wider critical engagement is necessary. Without this, it seems that PASS research, and by extension, university degrees, will continue to reproduce rather than disrupt the gender relations that have traditionally characterised our field.

\section{References}

Alfaro, É., \& Vázquez, B. (2007). La formación con perspectiva de género en los estudios de Ciencias de la Actividad Física y el Deporte. Paper presented at the Seminario 'Mujer y Deporte', Madrid.

Amsterdam, N., Knoppers, A., Claringbould, I., \& Jongmans, M. (2012). 'It's just the way it is...' or not? How physical education teachers categorise and normalise differences. Gender and Education, 24(7), 783-798. doi: 10.1080/09540253.2012.677013.

ANECA. (2005). Libro Blanco título de grado en Ciencias de la Actividad Física y del Deporte. [White Book in Physical Activity and Sport Science Degree] Madrid: ANECA.

ANECA. (2012). Guía de apoyo para la elaboración de la memoria de verificación de títulos oficiales universitarios. [Guideline for developing the official university titles report]. Madrid: ANECA.

Anguita, R. (2011). El reto de la formación del profesorado para la igualdad. [Teachers' challenges education for equality]. Revista Electrónica Interuniversitaria de Formación del Profesorado, 14(1), 43-51. Retrieved from www.aufop.com.

Aristizabal, P., \& Vizcarra, M. T. (2012). llustration of gender stereotypes in the initial stages of teacher training education. Education, 2(7), 347-355. doi: 10.5923/j.edu.20120207.19.

Arnot, M. (1982). Male hegemony, social class and women's education. Journal of Education, 164(1), 64-89. Retrieved from http://www.jstor.org/stable/42772889.

Arnot, M. (2002). The Complex Gendering of Invisible Pedagogies: Social reproduction or empowerment? British Journal of Sociology of Education, 23(4), 583-593. doi: 10.1080/0142569022000038431.

Arreman, I. E., \& Weiner, G. (2007). Gender, research and change in teacher education: a Swedish dimension. Gender and Education, 19(3), 317-337. doi: 10.1080/09540250701295478.

Ball, S. J., Maguire, M., \& Braun, A. (2012). How schools do policy: policy enactments in secondary schools. London: Routledge.

Bernstein, B. (1990). The structuring of pedagogic discourse. London: Routledge.

Bernstein, B. (2000). Pedagogy, symbolic control, and identity: theory, research, critique. United States of America: Rowman \& Littlefield.

Buitendijk, S., \& Maes, K. (2015). Gendered research and innovation. Retrieved from www.leru.org.

David, M. (2014). Feminism, Gender and Universities: Politics, Passion and Pedagogies. Farnham: Ashgate. 
Davies, K. (2008). Intersectionality as buzzword. A sociology of science perspective on what makes a feminist theory successful. Feminist Theory, 9(1), 67-85. doi: $10.1177 / 1464700108086364$.

Delamont, S. (2014). The heavy shadow? Bernstein and his legacy, British Journal of Sociology of Education, 35(3), 469-474. doi: 10.1080/01425692.2014.893073.

Department for Education. (2015). Carter review of initial teacher training. Retrieved from https://www.gov.uk/government/publications/carter-review-of-initialteacher-training.

Dewar, A. (1990). Oppression and privilege in physical education: struggles in the negotiation of gender in a university programme. In D. Kirk \& R. Tinning (Eds.), Physical education, curriculum and culture (pp. 67 -99). London: Falmer Press.

Donoso, T., \& Velasco, A. (2013). ¿Por qué una propuesta de formación en perspectiva de género en el ámbito universitario? [Why a proposal for gender training at university?]. Profesorado. Revista de curriculum y formación del profesorado, 17(1), 71-88. Retrieved from http://www.ugr.es/ recfpro/rev171ART5.pdf.

Dowling, F. (2008). Getting in touch with our feelings: The emotional geographies of gender relations in PETE. Sport, Education and Society, 13(3), 247-266. doi: 10.1080/13573320802200560.

Dowling, F. (2011). Are the PE teacher identities fit for postmodern schools or are they clinging to modernist notions of professionalism? A case estudy of norwegian PE teacher estudents emerging professional identities. Sport, Education and Society, 16(2), 201-222. doi: 10.1080/13573322.2011.540425.

Dowling, F. (2013). Teacher educator's gendered worplace tales. In G. Pfister \& M. K. Sisjord (Eds.), Gender and Sport. Changes and Challenges (pp. 217 -231). Münster: Waxmann.

Enright, E., \& O'Sullivan, M. (2010). 'Can I do it in my pyjamas?' Negotiating a physical education curriculum with teenage girls. European Physical Education Review, 16(3), 203-222. doi:10.1177/1356336X10382967.

Equal Opportunities Commission (1989). Formal Investigation Report: Initial Teacher Education in England and Wales. Manchester: Equal Opportunities Commission.

Evans, J., \& Davies, B. (2014). Physical Education PLC: neoliberalism, curriculum and governance. New directions for PESP research. Sport, Education and Society, 19(7), 869-884. doi: 10.1080/13573322.2013.850072.

Flintoff, A. (1993). Gender, physical education and initial teacher education. In J. Evans (Ed.), Equality, education and physical education (pp. 184 - 204). London: Falmer.

Flintoff, A., \& Fitzgerald, H. (2012). Theorizing difference and in(equality) in physical education, youth sport and health. In F. Dowling, H. Fitzgerald \& A. Flintoff (Eds.), Equity and difference in physical education, youth sport and health: a narrative approach (pp. 11 - 36). London: Routledge.

Francis, B. (2006). The nature of Gender. In C. Skelton, B. Francis \& L. Smulyan (Eds.), The Sage Handbook of Gender and Education (pp. 7 - 17). London: Sage.

Gore, J. (1993). The struggle for pedagogies: critical and feminist discourses as regimes of truth. London: Routledge. 
Gorely, T., Holroyd, R., \& Kirk, D. (2003). Muscularity, the habitus and the social construction of gender: towards a gender-relevant physical education. British Journal of Sociology of Education, 24(4), 429-448. doi: 10.1080/0142569032000109350.

Hay, P. J., \& Macdonald, D. (2010). The gendering of abilities in Senior PE. Physical Education and Sport Pedagogy, 15(3), 271-285. doi: 10.1080/17408980903150147.

Kårhus, S. (2010). Physical education teacher education on the education market who's defining what physical education teachers need to know? Physical Education and Sport Pedagogy, 15(3), 227-241. doi: 10.1080/17408980903150139.

Kårhus, S. (2012). Providers, consumers and the horizons of the possible: a case study of marketization and physical education teacher education pedagogical discouse. Sport, Education and Society, 17(2), 245-259. doi: 10.1080/13573322.2011.607953.

Kirk, D., \& Macdonald, D. (2001). The social construction of PETE in Higher Education: toward a research agenda. Quest, 53, 440-456. doi: 10.1080/00336297.2001.10491757.

Macdonald, D., Kirk, D., \& Braiuka, S. (1999). The social construction of the physical activity field at the school/university interface. European Physical Education Review, 5(1), 31-52. doi: 10.1177/1356336x990051003.

Maguire, M. (2006). Gender, education and development. In C. Skelton, B. Francis \& L. Smulyan (Eds.), The SAGE handbook of gender and education (pp. 93 - 108). London: SAGE Publications Ltd.

Márcia, A., Soler, S., Costes, A., \& Lavega, P. (2013). ¿Está bolonia en Cataluña? Configuración y desarrollo del nuevo plan de estudios en CAFyD en el INEFC: un estudio de caso. [Is 'bologna' in Cataluña? Configuration and development of the new curriculum in the physical activity and sport sciences degree at the INEFC: a case study]. Ágora para la EF y el Deporte, 15(2), 96-112. Retrieved from http://agorarevista.blogs.uva.es/files/2013/11/agora_15_2b_marcia_et_al.pdf.

Oliver, K., \& Kirk, D. (2014). Towards an activist approach to research and advocacy for girls and physical education. Physical Education and Sport Pedagogy. doi: 10.1080/17408989.2014.895803.

Organic Law 3/2007, of 22nd March, Effective Equality between men and women, BOE $71 \S 6115$ (2007).

Organic Law 4/2007, of 12 April, of Universities, BOE 89 § 7786 (2007).

Paechter, C. (2000). Changing school subjects: power, gender and curriculum. Buckingham: Open University Press.

Patton, M. Q. (1990). Qualitative evaluation and research methods. Newbury Park: Sage Publications.

Penney, D., \& Evans, J. (1999). Politics, policy and practice in physical education. London: Routledge. 
Pezzi, P., López, I., Marchant, A., Méndez, M. T., Ramos, E. M., Ruiz, M. B., \& Ybáñez, P. (2011). Universidad y feminismo: la integración transversal de los estudios de género en las prácticas docentes en Humanidades. Paper presented at the I Congreso Internacional Educación para la igualdad: Género y Sexualidades, Granada.

Pfister, G. (2010). Women in sport - gender relations and future perspectives. Sport in Society, 13(2), 234-248. doi: 10.1080/17430430903522954.

Prat, M., \& Flintoff, A. (2012). Taking the pulse of gender equity: a case study of physical education teacher education. Revista Electrónica Interuniversitaria de Formación del Profesorado, 15(3), 69-83. Retrieved from http://www.redalyc.org/articulo.oa?id=217026228001.

Scraton, S. (2013). Feminism and physical education: does gender still matter? In G. Pfister \& M. K. Sisjord (Eds.), Gender and sport. Changes and challenges (pp. 199 - 216). Münster: Waxmann Verlag GmbH.

Scraton, S., \& Flintoff, A. (2013). Gender, feminist theory, and sport. In D. L. Andrews \& B. Carrington (Eds.), A Companion to Sport (pp. 96 - 111). Oxford: WileyBlackwell.

Singh, P. (2002). Pedagogising Knowledge: Bernstein's theory of the pedagogic device. British Journal of Sociology of Education, 23(4), 571-582. doi: 10.1080/0142569022000038422.

Skelton, C., Francis, B., \& Smulyan, L. (2006). The Sage handbook of gender and education. London: SAGE Publications Ltd.

Soler, S. (2009). Reproduction, resistance and change processes of traditional gender relationships in physical education: the case of football. Cultura y Educación, 21(1), 31-42. doi: 10.1174/113564009787531253.

Svendsen, A.M. \& Svendsen, J.T. (2014).Teacher or coach? How logics from the field of sports contribute to the construction of knowledge in physical education teacher education pedagogical discourse through educational texts. Sport, Education and Society, doi: 10.1080/13573322.2014.956713.

Tomás, M. (2012). Conflictos en las universidades por razones de planes de estudios nuevos [Conflicts in universities for reasons of planned new studies]. In A. de la Herrán \& J. Paredes (Eds.), Promover el cambio pedagógico en la universidad (pp. 151-168). España: Pirámide.

Van Dijk, T. A. (2009). Society and discourse: How social contexts influence text and talk. Cambridge: Cambridge University Press.

Vertinsky, P. A. (1992). Reclaiming space, revisioning the body: the quest for gendersensitive physical education. Quest, 44(3), 373-396. doi: 10.1080/00336297.1992.10484063.

Webb, L., \& Macdonald, D. (2007). Techniques of power in physical education and the underrepresentation of women in leadership. Journal of Teaching in Physical Education, 26(3), 279-297. Retrieved from http://search.ebscohost.com/login.aspx?direct=true \&db=s3h\&AN=25732278\&site =ehost-live\&scope=site.

Weiner, G. (2000). A critical review of gender and teacher education in Europe. Pedagogy, Culture \& Society, 8(2), 233-247. doi: 10.1080/14681360000200091. 
Whatman, S., \& Singh, P. (2013). Constructing health and physical education curriculum for Indigenous girls in a remote Australian community. Physical Education and Sport Pedagogy. doi:10.1080/1748989.2013.868874.

With-Nielsen, N., \& Pfister, G. (2011). Gender constructions and negotiations in physical education: case studies. Sport, Education and Society, 16(5), 645-664. doi: 10.1080/13573322.2011.601145.

Wright, J. (2002). Physical education teacher education: sites of progress or resistance. In D. Penney (Ed.), Gender and physical education. Contemporary issues and future directions (pp. 190 - 207). London: Routledge. 